\title{
5-HTla receptor antagonists block perforant path-dentate LTP induced in novel, but not familiar, environments
}

\author{
Cyndy Davis Sanberg, ${ }^{1}$ Floretta L. Jones, ${ }^{2}$ Viet H. Do, Dario Dieguez Jr., \\ and Brian E. Derrick \\ The Department of Biology, The Cajal Neuroscience Research Institute, The University of Texas at San Antonio, \\ San Antonio, Texas 78249, USA
}

\begin{abstract}
Numerous studies suggest roles for monoamines in modulating long-term potentiation (LTP). Previously, we reported that both induction and maintenance of perforant path-dentate gyrus LTP is enhanced when induced while animals explore novel environments. Here we investigate the contribution of serotonin and 5-HTla receptors to the novelty-mediated enhancement of LTP. In freely moving animals, systemic administration of the selective 5-HTla antagonist WAY-100635 (WAY) attenuated LTP in a dose-dependent manner when LTP was induced while animals explored novel cages. In contrast, LTP was completely unaffected by WAY when induced in familiar environments. LTP was also blocked in anesthetized animals by direct application of WAY to the dentate gyrus, but not to the median raphe nucleus (MRN), suggesting the effect of systemic WAY is mediated by a block of dentate 5-HTla receptors. Paradoxically, systemic administration of the 5-HTla agonist 8-OH-DPAT also attenuated LTP. This attenuation was mimicked in anesthetized animals following application of 8-OH-DPAT to the MRN, but not the dentate gyrus. In addition, application of a 5-HTla agonist to the dentate gyrus reduced somatic GABAergic inhibition. Because serotonergic projections from the MRN terminate on dentate inhibitory interneurons, these data suggest 5-HTla receptors contribute to LTP induction via inhibition of GABAergic interneurons. Moreover, activation of raphe 5-HTla autoreceptors, which inhibits serotonin release, attenuated LTP induction even in familiar environments. This suggests that serotonin normally contributes to dentate LTP induction in a variety of behavioral states. Together, these data suggest that serotonin and dentate 5-HTla receptors play a permissive role in dentate LTP induction, particularly in novel conditions, and presumably, during the encoding of novel, hippocampus-relevant information.
\end{abstract}

Long-term potentiation (LTP) remains the most intensively studied model of the cellular mechanisms of synaptic plasticity that may underlie memory (Bliss and Lomo 1973; Bliss and Collingridge 1993). Previously, we and others reported that the magnitude and longevity of LTP is enhanced when LTP is induced while animals explore novel environments, suggesting that behavioral states that involve novelty, and presumably learning, are optimal for synaptic plasticity (Davis and Derrick 1997; Straube et al. 2003a; Davis et al. 2004; Kemp and ManahanVaughan 2004). In line with this finding, it is suggested that novelty engages the hippocampal formation in a distinct "mode" of operation that appears optimal for inducing synaptic plasticity, and presumably, encoding (Buzsaki 1989; Paulsen and Moser 1998; Vinogradova 2001; Hasselmo et al. 2002; Lisman and Otmakhova 2002; Davis et al. 2004; Guzowski et al. 2004).

A number of studies suggest that the enhancement of LTP by novelty is mediated by monoaminergic neuromodulators (Bramham et al. 1997; Paulsen and Moser 1998; Li et al. 2003; Straube et al. 2005b). Previous studies strongly support roles for both norepinephrine (Kitchigina et al. 1997; Straube et al. 2003a) and dopamine (Li et al. 2003) in either the excitatory effects of novel stimuli on dentate responses (Kitchigina et al. 1997) or the

\footnotetext{
1Present address: Saneron CCEL Therapeutics, Inc., UTC II, Tampa, Florida 33612, USA.

${ }^{2}$ Corresponding author.

E-mail fljones@utsa.edu; fax (210) 458-5658.

Article and publication are at http://www.learnmem.org/cgi/doi/10.1101/ Im.126306.
}

enhanced synaptic plasticity with exposure to novelty (Straube et al. 2003b). Serotonin (5-HT) also is a potential candidate for modulating synaptic plasticity with novel stimuli (Kemp and Manahan-Vaughan 2004), as serotonin is thought to play an important role in arousal and tasks involving either novel stimuli or high cognitive demands (Buhot and Naili 1995; Buhot 1997). Serotonergic projections to the dentate arise from the median raphe nucleus (MRN), and preferentially innervate GABAergic interneurons within the hippocampus and dentate gyrus (Freund et al. 1990, 1992; Halasy et al. 1992). Previous studies report that serotonin releasers facilitate the response of dentate granule cells to perforant path stimulation (Winson 1980; Richter-Levin and Segal 1990), an effect that is thought to be mediated by the 5-HT1a receptor type (Levkovitz and Segal 1997). It is suggested that the excitatory effects mediated by dentate 5-HT1a receptors results from the enhancement of afferent responsivity by 5 -HT1a receptors (Levkovitz and Segal 1997), or a 5-HT1a receptormediated inhibition of GABAergic interneurons or GABA release (Freund et al. 1990; Freund 1992; Halasy et al. 1992; Kao et al. 1997; Gulyás et al. 1999; Nitz and McNaughton 1999).

The contribution of serotonin to LTP induction in the hippocampal formation remains poorly defined. Although depletion of serotonin is reported to attenuate perforant path-dentate gyrus LTP in intact animals (Bliss et al. 1983), LTP induction in the dentate gyrus is not altered in hippocampal slices taken from serotonin-depleted animals (Stanton and Sarvey 1985). In addition, 5-HT1a receptor activation generally has an inhibitory effect on LTP at perforant path-dentate synapses in vitro (Sakai and 
Tanaka 1993; Kojima et al. 2003; Tachibana et al. 2004). These effects may reflect an attenuation of LTP via the 5-HT1a receptormediated hyperpolarization observed in principal cells of the hippocampal formation (Segal 1990; Piguet and Galvan 1994; Gulyás et al. 1999). However, the behavioral modulation of serotonin is not possible in vitro, and an intact serotonergic system is essential to assess the contribution of endogenous serotonin to LTP induction among different behavioral states (Winson 1980; Bliss et al. 1983; Klancnik and Phillips 1991; Srebro et al. 1982).

Here, we demonstrate that systemic administration of the highly selective 5-HT1a receptor antagonist WAY-100,635 (WAY) blocks the induction of medial perforant path-dentate LTP in a dose-dependent manner in intact, behaving animals. Interestingly, the sensitivity of dentate LTP induction to 5-HT1a antagonism is dependent upon the environmental conditions; WAY effectively blocks LTP induced while animals explore novel cages, but has no effect on LTP when it is induced while animals explore familiar cages. As GABAergic inhibition normally is increased during exploration of novel environments (Moser 1996) and enhanced GABA inhibition attenuates LTP induction (Wigstrom and Gustafsson 1985), it seems plausible that WAY blocks LTP induction by blocking the disinhibitory effects of 5-HT1a receptors. Our previous studies (Davis et al. 2004) suggest that novelty engages the dentate gyrus in a "mode" that is optimal for inducing synaptic plasticity. Together, these data suggest that both serotonin and 5-HT1a receptors in the dentate exert an excitatory effect that plays a permissive role in LTP induction, particularly in environments with a high degree of novelty. Some of these data were presented previously (Davis-Hart and Derrick 2001).

\section{Results}

\section{5-HTla antagonists block LTP induction in novel,} but not familiar, environments

We first examined the effects of systemic administration of the 5-HT1a antagonist WAY on LTP induction during exploration of novel environments. Previously, we reported that LTP induced during the initial exploration of a novel cage results in an increase in the magnitude and the duration of LTP, an effect that is independent of overall activity, the presence of theta rhythm, and changes in brain temperature (Davis et al. 2004). These findings suggest that novel stimuli within the environment initiate a state that is optimal for the induction of dentate LTP (Davis et al. 2004). Here, we assessed the effects of the 5-HT1a antagonist WAY on perforant path-dentate LTP induction (see Fig. 1) while the animal explored a novel cage.

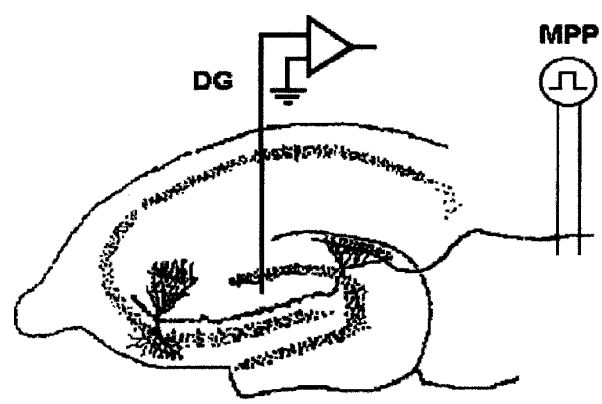

Figure 1. Schematic diagram of the in vivo preparation used in both anesthetized animals and awake animals for recording monosynaptic perforant path (MPP) responses in the dentate gyrus (DG). Field potentials were evoked by stimulation of the medial aspect of the angular bundle, and responses were recorded in the dentate hilus using either a single stainless steel Teflon-coated electrode or an insulated 33-g cannula, exposed only at the tip.
The 5-HT1a antagonist WAY-100635, in doses of 0.005, 0.01 , or $0.5 \mathrm{mg} / \mathrm{kg}$, had no discernable effect on field EPSP slopes 20-25 min following administration, even at the highest dose tested (Fig. 2A). Twenty-five minutes after administration of WAY or vehicle, animals were placed in an identically sized cage containing novel objects, as described previously (Davis et al. 2004). After a 5-min period of exploration, LTP was induced with five theta trains delivered at 20 -sec intervals, after which the animals were returned immediately to their home cage. LTP was measured 56-60 min later in the home cage. Animals that received the water vehicle displayed LTP with an average increase in field EPSP slopes of $137 \pm 3 \%(n=4$; Fig. $2 A)$, a magnitude comparable to the magnitude of LTP induced in novel (as opposed to familiar) environments reported in our previous study (Davis et al. 2004). LTP was attenuated by WAY-100635 in a dose-dependent manner $\left(F_{(3,12)}=5.15, P<0.05\right)$. LTP was attenuated significantly by WAY with both the 0.01 and $0.5 \mathrm{mg} / \mathrm{kg}$ doses, with LTP magnitude measured at 56-60 min, averaging $107 \pm 3 \%$ with the $0.5 \mathrm{mg} / \mathrm{kg}$ dose $(n=4)$ and $110 \pm 10 \%$ with the $0.01 \mathrm{mg} / \mathrm{kg}$ dose $(n=4, P<0.05$, Tukey test). The $0.005 \mathrm{mg} /$ $\mathrm{kg}$ dose had no significant effect on LTP magnitude (136 $\pm 5 \%$, $n=4, P>0.05$, Tukey test) when compared with animals receiving only the water vehicle.

We also observed a dose-dependent effect of WAY on LTP longevity (Fig. 2B). Vehicle-treated animals displayed LTP with an extended time course $(\sim 14 \mathrm{~d})$ typical of LTP when induced in a novel environment (Davis et al. 2004). The $0.5 \mathrm{mg} / \mathrm{kg}$ dose of WAY blocked LTP induction and LTP over the entire 2-wk period. The 0.01 dose of WAY produced LTP with a delayed onset that decayed in $\sim 7 \mathrm{~d}$, whereas the lowest dose $(0.005 \mathrm{mg} / \mathrm{kg})$ did not alter LTP magnitude or LTP duration, and displayed LTP with an extended (2-wk) time course typical of LTP induced in novel environments (Davis et al. 2004).

Although WAY was effective in blocking LTP in novel environments, a completely different effect was observed when LTP was induced in the animal's home cage (Fig. 3A). WAY, in the dose effective in blocking LTP in novel environments $(0.5 \mathrm{mg} /$ $\mathrm{kg}$ ), had no effect on LTP when induced in the familiar home cage $(144 \pm 9 \%, n=5)$, and the magnitude of LTP at $1 \mathrm{~h}$ did not differ from LTP in animals that received only the water vehicle $(132 \pm 3 \%, n=4, P>0.05)$. In contrast, the $0.5 \mathrm{mg} / \mathrm{kg}$ dose of WAY blocked LTP when induced while animals explored a novel cage $\left(107 \pm 9 \%, n=4, F_{(1,7)}=7.99, P<0.05\right)$. LTP was blocked over subsequent days in WAY-treated animals, whereas LTP induced in a novel cage with WAY on board displayed a time course similar to LTP induced in familiar environments (Fig. 3B; Davis et al. 2004). The 5-HT1a antagonists are reported to display anxiolytic properties, thus a difference in activity might be observed in the different environments (Davis et al. 2004), as activity can alter evoked responses (Erickson et al. 1991) by altering brain temperature (Moser et al. 1993). However, measures of total activity over the 5-min period of exploration $30 \mathrm{~min}$ following administration of the highest dose of WAY $(0.5 \mathrm{mg} / \mathrm{kg})$ revealed no differences in total activity in a novel cage when compared with animals in a familiar cage (Fig. 3C; $P<0.05$ ). Taken together, these data indicate that 5-HT1a receptor activation is necessary for LTP induction when LTP is induced in novel, but not familiar environments. Thus, the effects of WAY are both dose dependent and dependent upon novel stimuli, and presumably, the behavioral state of the animal.

\section{WAY blocks LTP induction when applied directly} to the dentate gyrus in pentobarbital-anesthetized animals Although systemic administration of WAY may have altered LTP induction by acting on 5-HT1a receptors within the dentate gyrus (Levkovitz and Segal 1997), WAY also may have altered LTP 

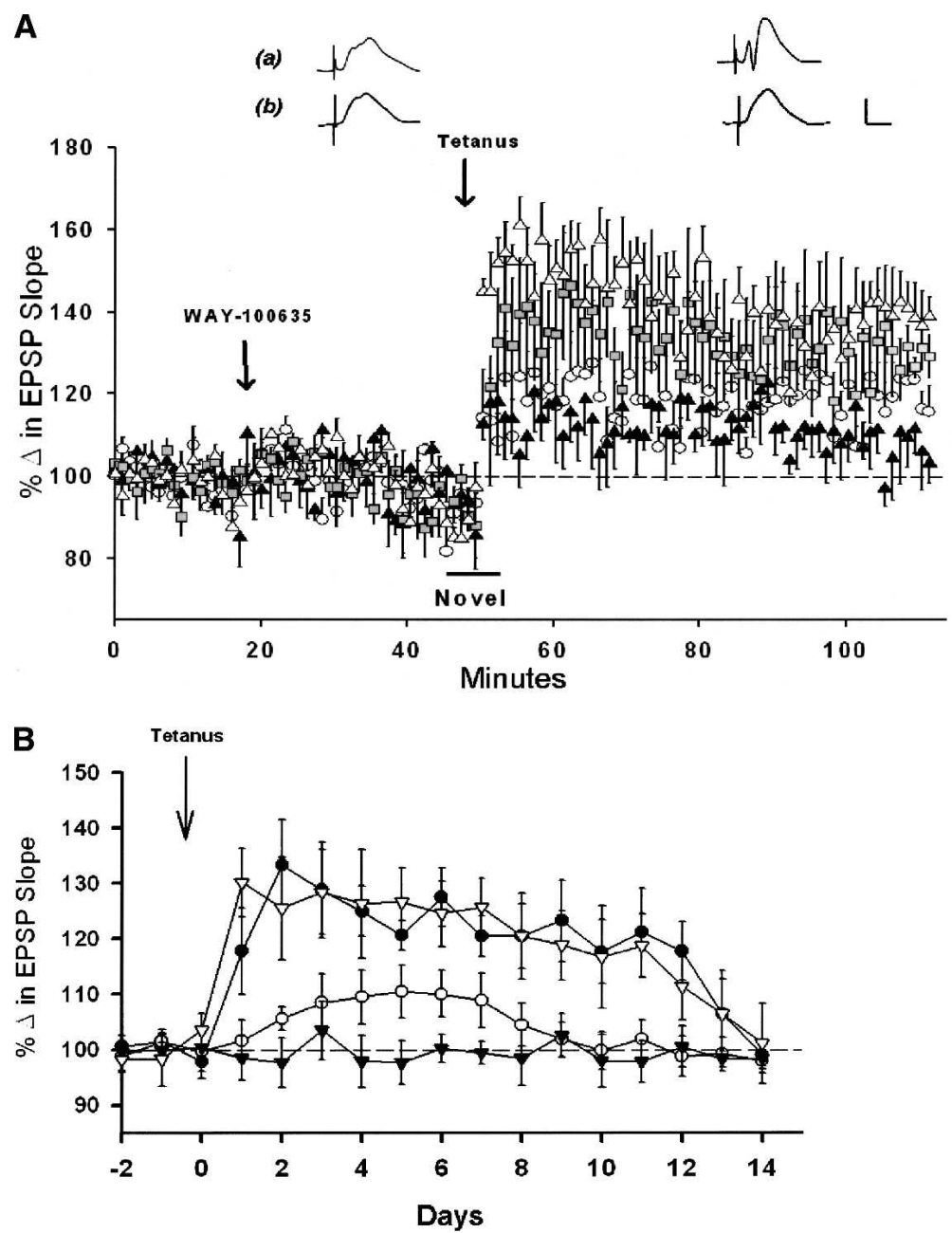

Figure 2. Systemic administration of WAY-100635 (WAY) blocks LTP induction in awake freely moving animals exploring novel environments. (A) Point plot of averaged medial perforant pathdentate field EPSP slopes ( \pm SEM) showing baseline responses, responses 25-30 min after application of drug, and $1 \mathrm{~h}$ following tetanus. Systemic WAY attenuated LTP in doses of $0.5(\boldsymbol{\Delta})$ and $0.01 \mathrm{mg} / \mathrm{kg}$ (O), $(P<0.05)$. The $0.005 \mathrm{mg} / \mathrm{kg}$ dose $(\square)$ did not differ significantly from controls receiving only the water vehicle $(\triangle),(n=4 /$ group). Traces are representative responses collected $20-25$ min following administration of either (a) the water vehicle or (b) $0.5 \mathrm{mg} / \mathrm{kg}$ of WAY, and responses collected $1 \mathrm{~h}$ after delivery of $\theta$ trains. Calibration: $1 \mathrm{mV}, 5 \mathrm{msec}$. (B) Comparison of the time course of LTP over a 2-wk period induced following administration of the water vehicle $(\nabla)$ or $0.005(\bullet), 0.01(0)$ or $0.5 \mathrm{mg} / \mathrm{kg}$ of WAY $(\boldsymbol{\nabla}),(n=4 /$ group). WAY in doses of 0.01 and $0.5 \mathrm{mg} / \mathrm{kg}$ attenuated significantly the duration of LTP as compared with LTP induced in the presence of the vehicle $(P<0.05)$.

by blocking other 5-HT1a receptor populations. Among such receptor populations are the 5-HT1a autoreceptors in the raphe nuclei, which, when activated, reduce raphe activity and serotonin release (Cadogan et al. 1994; Kreiss and Lucki 1994; Mundey et al. 1996; Terreni et al. 1996). Thus, WAY may have blocked LTP by blocking raphe 5-HT1a autoreceptors that normally inhibit serotonin release. This would suggest the alternative hypothesis that increased, rather than decreased release of serotonin underlies the WAY-mediated blockade of LTP, consistent with previous in vitro studies (Sakai and Tanaka 1993).

We first addressed the locus of the 5-HT1a receptors involved in LTP induction by applying WAY directly to the dentate gyrus in pentobarbital-anesthetized animals. Local application of 1,3 , or $7 \mathrm{nmol}$ quantities of WAY or the lactated Ringer's vehicle (1.0 $\mu \mathrm{L}$ volume) produced no discernible effects on the magnitude of baseline field EPSP slopes $\left(F_{(3,8)}=0.47, P>0.05\right.$; Fig. 4$)$.
However, locally applied WAY blocked the induction of dentate LTP in a dosedependent manner $\left(F_{(3,8)}=14.60\right.$, $P<0.01$; Fig. 4 ), and a significant attenuation of LTP magnitude was observed with the 7 -nmol quantity $(116 \pm 7 \%$, $n=3$ ) as compared to animals that received the lactated Ringer's vehicle $(169 \pm 2 \% ; n=3, P<0.05$, Tukey test). Neither the $1 \mathrm{nmol}(170 \pm 7 \%, n=3)$ nor the 3 nmol (142 $\pm 9 \%, n=3)$ quantity of WAY altered significantly LTP magnitude $(P>0.05$, Tukey test). In addition, short-term potentiation (STP) of field EPSP slopes measured over the 5 -min period after delivery of $\theta$ bursts also was attenuated (Fig. 4), and the magnitude of LTP measured after $1 \mathrm{~h}$ covaried with the magnitude of the initial short-term potentiation $\left(\mathrm{r}^{2}=0.76\right.$, $P<0.05, n=9$ ). Thus, application of WAY directly to the dentate gyrus attenuated LTP and STP in a dosedependent manner.

\section{Systemic administration of a 5-HTla agonist also attenuates LTP}

If serotonin and 5-HT1a receptor activation normally facilitates LTP induction in novel environments, then it would be predicted that administration of the 5-HT1a receptor agonist in familiar conditions might enhance LTP in the absence of novelty. This was tested using the selective 5-HT1a receptor agonist 8-OH-DPAT $(0.3 \mathrm{mg} / \mathrm{kg})$ administered systemically (i.p.) $30 \mathrm{~min}$ prior to LTP induction. Twenty-five minutes after administration, animals were lifted and reoriented in their home cage (in order to control for handling that is necessary to place animals in the novel environment, see Materials and Methods), and LTP was induced with theta trains 5 min later. However, rather than augmenting LTP, this dose of 8-OH-DPAT attenuated LTP $(115 \pm 6 \%, n=4$, Fig. 5A). In contrast, animals receiving only water vehicle displayed LTP typically seen in awake animals (138 $\pm 8 \%, n=3$; $\left.F_{(1,5)}=43.51, P<0.05\right)$.

\section{5-HTla agonists and 5-HTla antagonists block LTP via actions at different sites}

The inhibition of LTP by systemic 8-OH-DPAT is the opposite of what would be expected if the activation of dentate 5-HT1a receptors normally contributes to LTP induction. However, in addition to postsynaptic 5-HT1a receptors, 5-HT1a autoreceptors of the raphe nuclei are activated by systemic 8-OH-DPAT. These receptors are reported to be highly sensitive to 8-OH-DPAT, and often dominate the effects of systemic 5-HT1a agonists when compared with their effects on dentate responses (Jolas et al. 1995). Activation of raphe 5-HT1a autoreceptors inhibits raphe activity (Jolas et al. 1995), and the dose of 8-OH-DPAT used here

\section{Learning \& Memory}

www.learnmem.org 

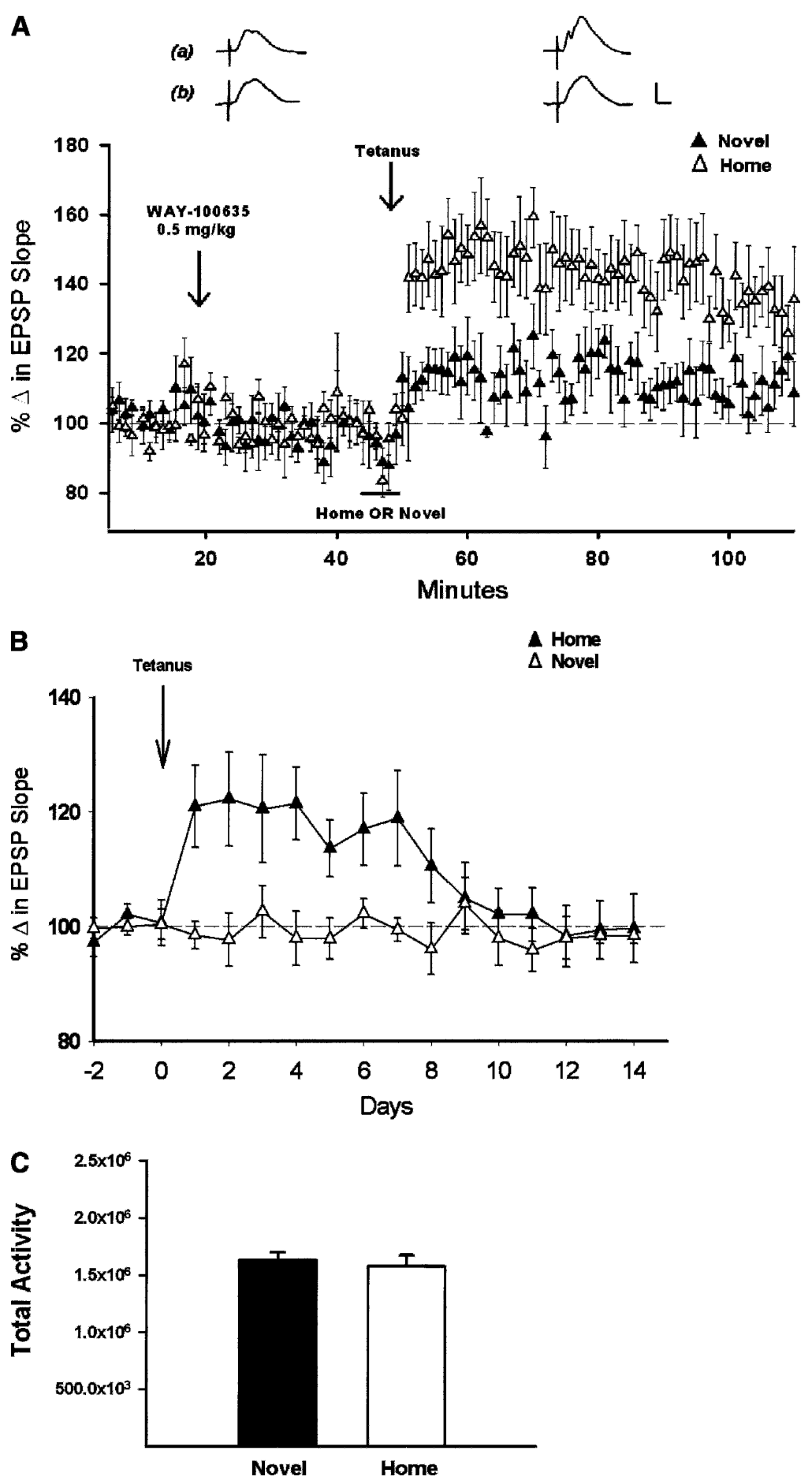

Figure 3. Systemically administered WAY blocks LTP in novel, but not familiar, environments. (A) Comparison of the effects of the $0.5-\mathrm{mg} / \mathrm{kg}$ dose of WAY on LTP induced while animals explored either a novel $(\boldsymbol{\Delta}),(n=4)$ or a familiar $(\triangle),(n=5)$ cage $( \pm$ SEM). WAY blocked LTP induced in the novel environment, but did not alter LTP induced in the familiar home cage. Traces are representative responses collected $20-25$ min after drug administration, and $1 \mathrm{~h}$ after delivery of $\theta$ trains in either familiar (a) or novel (b) conditions. Calibration: $1 \mathrm{mV}, 5 \mathrm{msec}$. (B) Comparison of the time course of LTP induced after administration of $0.5 \mathrm{mg} / \mathrm{kg}$ WAY in either the novel $(\triangle),(n=4)$ or the familiar home environment $(\boldsymbol{\Delta}),(n=4)$. LTP was observed $24 \mathrm{~h}$ later only when induced in a familiar environment. (C) Measures of total activity over the 5 -min period of exploration in a novel or a familiar cage 25-30 min following systemic administration of $0.5 \mathrm{mg} / \mathrm{kg}$ WAY ( $n=4 / \mathrm{group}$ ). Activity measures reflect the total number of pixels detecting contrast changes in the caged area $(1080 \times 3250$ pixels). WAY had no effect on the total activity of animals as measured in a novel environment $(P>0.05)$.
$(0.3 \mathrm{mg} / \mathrm{kg})$ is known to reduce serotonin release via activation of raphe autoreceptors and inhibition of raphe activity (Cadogan et al. 1994; Kreiss and Lucki 1994; Terreni et al. 1996;). Thus, rather than blocking LTP by activating dentate 5-HT1a receptors, systemic 8-OHDPAT is more likely to have blocked LTP by activating raphe 5-HT1a autoreceptors and reducing serotonin release.

To address this possibility, we determined the locus of action of 8-OH-DPAT by applying 8-OH-DPAT to either the dentate gyrus or the MRN, reasoning that if an attenuation of LTP by $8-\mathrm{OH}-$ DPAT is due to activation of dentate 5-HT1a receptors, then direct application of 8-OH-DPAT to the dentate would similarly attenuate LTP. However, application of a 10-nmol quantity of $8-\mathrm{OH}-$ DPAT directly into the dentate $10 \mathrm{~min}$ prior to delivery of theta trains did not alter LTP magnitude $(158 \pm 11 \%, n=3)$ as compared with LTP observed in animals receiving the lactated Ringer's vehicle $\left(169 \pm 2 \%, n=3 ; F_{(1,4)}=1.12\right.$, $P>0.05$; Fig. 5B). In contrast, application of a $10-\mathrm{nmol}$ quantity of $8-\mathrm{OH}-$ DPAT to the MRN 10 min prior to theta trains attenuated significantly LTP $(126 \pm 6 \%, n=3)$ as compared with animals receiving only the Ringer's vehicle $\left(159 \pm 5 \%, n=4 ; F_{(1,4)}=18.19\right.$, $P<0.05$; Fig. 5C).

The above data indicate $8-\mathrm{OH}$ DPAT is effective in blocking LTP when administered systemically or when applied directly to the MRN, but not the dentate gyrus. Conversely, as WAY blocks LTP when administered systemically or when applied to the dentate, we therefore assessed the effects of WAY applied locally to the MRN on LTP induction. Here, we used the same quantity of WAY found effective in blocking LTP when applied to the dentate $(7 \mathrm{nmol})$. However, WAY applied directly to the MRN had no effect on LTP magnitude $(157 \pm 6 \%)$ as compared with animals receiving lactated Ringer's vehicle $\left(153 \pm 12 \%, n=3 ; F_{(1,5)}=0.20, P>0.05\right.$, Fig. 5D). These data indicate that systemic 8-OH-DPAT attenuates LTP via activation of 5-HT1a receptors in the MRN. Conversely, systemic WAY blocks LTP via the blockade of postsynaptic 5-HT1a receptors within the dentate.

\section{The 5-HTla agonist 8-OH-DPAT} elicits both excitatory and inhibitory actions on evoked perforant path-dentate responses The MRN projections to the dentate gyrus synapse primarily on GABAergic inhibitory interneurons, and thus are the 


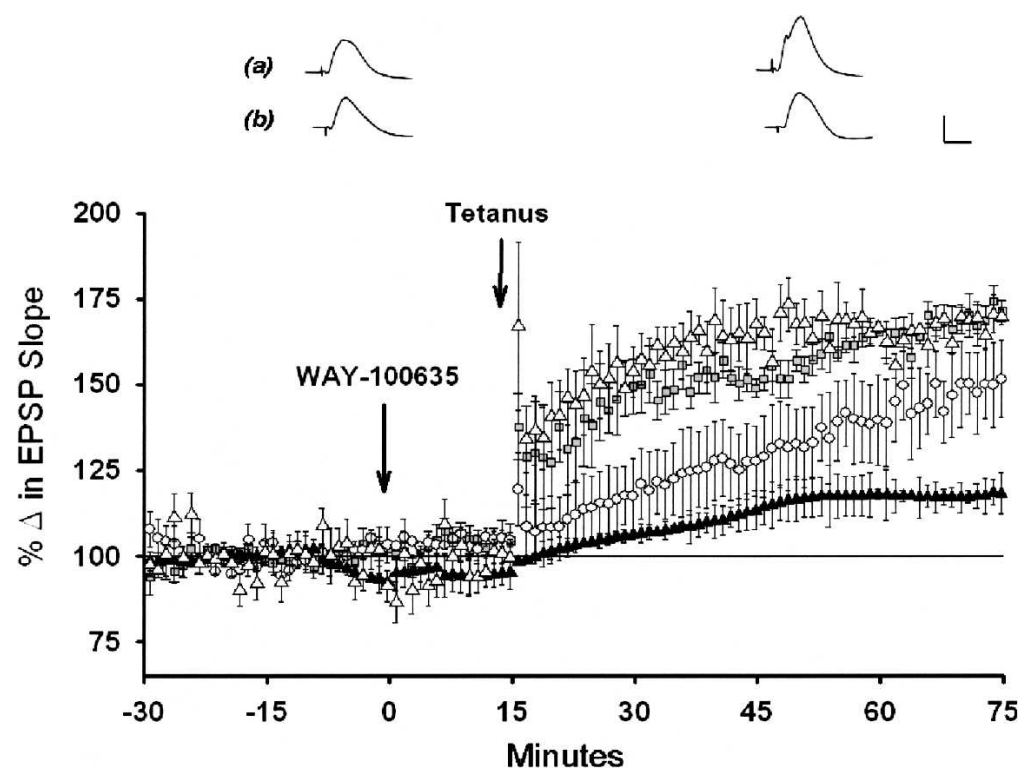

Figure 4. Direct application of WAY to the dentate gyrus blocks LTP induction in pentobarbitalanesthetized animals. Plot of medial perforant path-dentate field EPSP slopes ( \pm SEM) following the application of WAY or the lactated Ringer's vehicle to the dentate and $1 \mathrm{~h}$ following theta trains. The $7 \mathrm{nmol}(\boldsymbol{\Lambda})$ and $3 \mathrm{nmol}(0) \mathrm{nmol}$ quantities of WAY significantly attenuated LTP magnitude, whereas the $1 \mathrm{nmol}(\square)$ did not alter LTP magnitude as compared with LTP observed following application of the lactated Ringer's vehicle $(\triangle),(n=3 /$ group, $P<0.05)$. In addition, the initial short-term potentiation (STP), reflected in magnitude of potentiation immediately after delivery of theta trains, also was attenuated dose dependently by WAY $(P<0.05)$. Traces are representative of responses collected 5-10 min after application of the vehicle (a) or a 7-nmol quantity of WAY (b), and $1 \mathrm{~h}$ after delivery of $\theta$ trains. Calibration: $1 \mathrm{mV}, 5 \mathrm{msec}$.

primary target for the effects of serotonin in the dentate gyrus (Freund 1992). If a 5-HT1a receptor-mediated inhibition of GABAergic interneurons contributes to dentate LTP induction, 5-HT1a agonists should display disinhibitory effects. This was addressed directly by assessing the effect of a 10-nmol quantity of 8-OH-DPAT on paired pulse inhibition (PPI) of both the population spike and paired pulse depression (PPD) of synaptic responses that are observed in the dentate (Moser 1996).

Both PPI and PPD were assessed before and after application of a 10-nmol quantity of 8-OH-DPAT to the dentate using paired pulse stimulation at intervals of 30-200 msec. Shortly after application, 8-OH-DPAT phasically increased the magnitude of the initial population spike (Fig. 6A) as reported previously (Klancnik et al. 1989; Levkovitz and Segal 1997). This excitatory effect was short lived ( 5-10 min), and was accompanied by a slowly developing depression of synaptic responses that lasted 10-15 min (Fig. 6A). This depression of perforant path synaptic responses recovered over a longer time period ( 15-20 min after initiation of 8-OH-DPAT application) than did the increase in population spikes (cf. Fig. 6A and Fig. 5A).

8-OH-DPAT also was observed to abolish inhibition of the population spike observed in the second evoked response at intervals of $30-100 \mathrm{msec}\left(F_{\operatorname{int}(6,12)}=6.74, P<0.01\right.$; Fig 6B). However, PPD of the field EPSP slope, an effect mediated partially by feedback dendritic inhibition (Moser 1996), was not altered significantly by 8 -OH-DPAT at any interval $\left(F_{(2,12)}=1.18, P>0.05\right.$; Fig. 6C). The excitatory and disinhibitory effects of 8-OH-DPAT were short lived (5-10 min), after which population spike magnitude and paired-pulse inhibition returned to baseline levels. Thus, application of 8-OH-DPAT to the dentate gyrus induces phasic excitatory effects accompanied by both a reduction in somatic GABAergic inhibition (Gulyás et al. 1999) and a slowly developing depression of synaptic responses, although signifi- cant effects on dendritic inhibition, as measured by paired-pulse depression, were not detected.

\section{Discussion}

The present results indicate that the selective 5-HT1a receptor antagonist WAY-100635 blocks the induction of perforant path-dentate LTP in a dosedependent manner in anesthetized and behaving animals. In behaving animals, WAY was effective only when animals explored novel environments. However, WAY was without any effect on LTP when induced in the familiar home cage. Thus, the activation of 5-HT1a receptors by serotonin is crucial for inducing LTP. However, the contribution of 5-HT1a receptors to LTP induction in behaving animals appears to be limited to conditions with a high degree of novelty, serving as another example of the behavioral modulation of hippocampal function mediated by serotonin (Winson 1980; Srebro et al. 1982). Moreover, the contribution of 5-HT1a receptors to LTP induction is likely mediated by the disinhibitory effects of 5-HT1a receptors within the dentate gyrus, as LTP was blocked by direct application of WAY to the dentate gyrus, and application of the 5-HT1a agonist 8-OH-DPAT attenuated paired-pulse inhibition. Thus, serotonin release and the activation of dentate 5-HT1a receptors likely contribute to the enhanced induction of LTP observed in novel environments (Davis et al. 2004) via a phasic attenuation of GABAergic inhibition.

\section{Serotonin normally contributes to LTP induction}

Paradoxically, systemic administration of the 5-HT1a agonist 8-OH-DPAT also attenuated dentate LTP induction. How could systemic administration of 5-HT1a antagonists and 5-HT1a agonists both attenuate LTP induction? Direct application of 8-OHDPAT to the dentate gyrus did not alter LTP, suggesting that the effect of 8-OH-DPAT must be mediated by the activation of 5-HT1a receptors external to the dentate gyrus. A likely target is the somatodendritic 5-HT1a autoreceptors of the raphe nuclei, which are highly sensitive to 8-OH-DPAT (Jolas et al. 1995), and reduce raphe neuronal activity and 5-HT release (Hjorth and Magnusson 1988; Cadogan et al. 1994; Kreiss and Lucki 1994; Jolas et al. 1995). We found that application of 8-OH-DPAT directly to the MRN also attenuated LTP to the same degree as was observed with systemically administered 8-OH-DPAT. Thus, systemic 8-OH-DPAT likely exerts its effects via activation of raphe 5-HT1a autoreceptors, and the subsequent reduction in serotonin release (Hjorth and Magnusson 1988; Kreiss and Lucki 1994). In contrast, local application of the 5-HT1a antagonist WAY blocks LTP in the dentate, but has no effect on LTP when applied to the MRN. This suggests that this 5-HT1a antagonist blocks LTP by blocking postsynaptic 5 -HT1a receptors within the dentate gyrus. The lack of any effect of WAY on LTP when applied to the MRN is consistent with previous findings indicating that this 5-HT1a antagonist has little effect on raphe activity, as these receptors normally may be unoccupied, and are even referred to as "silent" 5-HT1a autoreceptors (Fletcher et al. 1996). Thus, systemic administration of a 5-HT1a antagonist and 5-HT1a agonist 

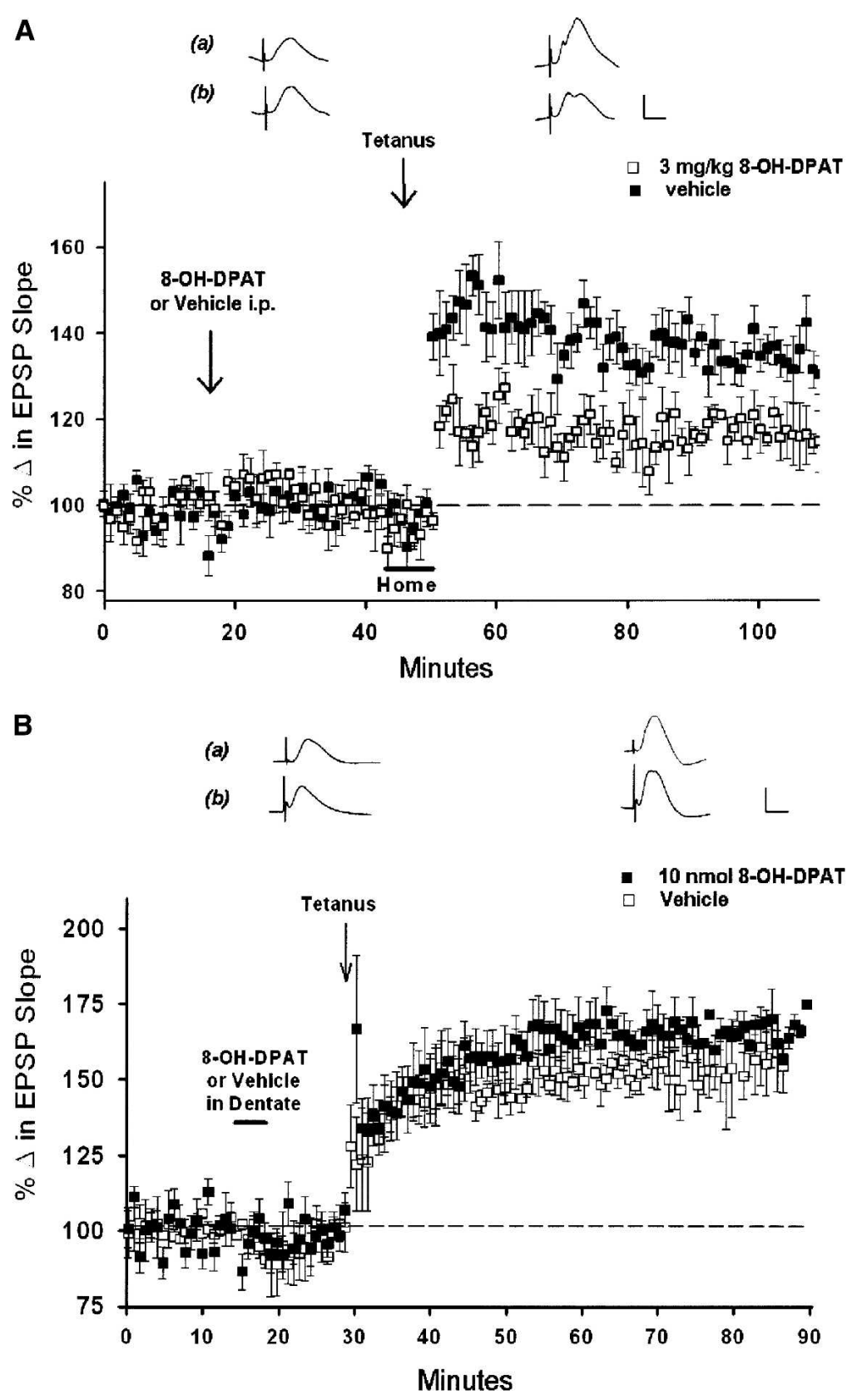

Figure 5. (Continued on next page).

both block LTP via actions at distinct sites. Systemic administration of this 5-HT1a antagonist blocks LTP via blocking postsynaptic 5-HT1a receptors in the dentate gyrus. By contrast, the relatively greater efficacy of 8-OH-DPAT at 5-HT1a autoreceptors in the MRN (Jolas et al. 1995) suggests that systemic administration of this agonist attenuates LTP via activation of 5-HT1a autoreceptors, and, presumably, a reduction in serotonin release. Importantly, although the 5-HT1a agonist and the 5-HT1a antagonist exert their effects at distinct sites, both drugs reduce the actions of serotonin in the dentate, and both drugs attenuate the induction of LTP.

Interestingly, systemic administration of the 5-HT1a agonist 8-OH-DPAT was observed to attenuate LTP induction. This was observed in familiar environments, a condition in which 5-HT1a antagonists have no apparent effects, and thus normally do not contribute to LTP. Because 8-OH-DPAT likely exerts its effects in the MRN via reducing neuronal activity and 5-HT release (Cadogan et al. 1994; Kreiss and Lucki 1994; Terreni et al. 1996), together these data suggest that a reduction in raphe activity and serotonin release attenuates LTP induction. As this is observed in conditions where 5-HT1a receptor activation is not necessary for LTP induction, it is likely that the activation of 5-HT receptors other than the 5-HT1a receptor (e.g., 5-HT4 receptors; see Kemp and Manahan-Vaughan 2004; Marchetti et al. 2004) also may be necessary for the full induction of dentate LTP, even in familiar environments. Thus, serotonin contributes to LTP in a variety of behavioral states and normally contributes to the full induction of dentate LTP in vivo (Bliss et al. 1983).

\section{5-HTla receptors may contribute to LTP induction via their disinhibitory actions}

Serotonergic neurons of the MRN send substantial projections to the dentate gyrus (Segal 1990; Halasy et al. 1992; Freund 1992), and form synaptic contacts with a variety of GABAergic interneurons thought to mediate both dendritic and somatic inhibition (Freund et al. 1990; Segal 1990; Halasy et al. 1992). It is thought that serotonin reduces GABAergic inhibition via activation of inhibitory 5-HT1a receptors on GABAergic interneurons (Halasy et al. 1992; Levkovitz and Segal 1997; Gulyás et al. 1999). In support of a disinhibitory role of 5-HT release in the hippocampal formation, application of 8-OH-DPAT to the MRN increases the activity of hippocampal inhibitory interneurons (Nitz and McNaughton 1999), whereas stimulation of the MRN inhibits dentate interneurons (Kao et al. 1997). Consistent with this view, we observed an attenuation of paired-pulse inhibition in perforant path-dentate population spike responses following application of 8-OH-DPAT to the dentate, a result indicating a reduction in feedback (somatic) GABAergic inhibition.

However, we did not observe any alteration of paired-pulse depression of field EPSPs, suggesting dendritic inhibition was unaffected by this drug (Moser 1996). Previous studies suggest 5-HT projections to the dentate innervate primarily GABAergic interneurons mediating dendritic inhibition (Freund 1992; Halasy et al. 1992). As the somata of interneurons receiving 5-HT projections reside in the granule cell layer, these cells may correspond to the HIPP or HICAP interneurons of Freund and Buzsaki (1996), as both have their soma in the granule cell layer, and both mediate dendritic inhibition. However, these interneurons often project to discrete laminae in the dentate molecular layer, suggesting that attenuated dendritic inhibition may be localized to 

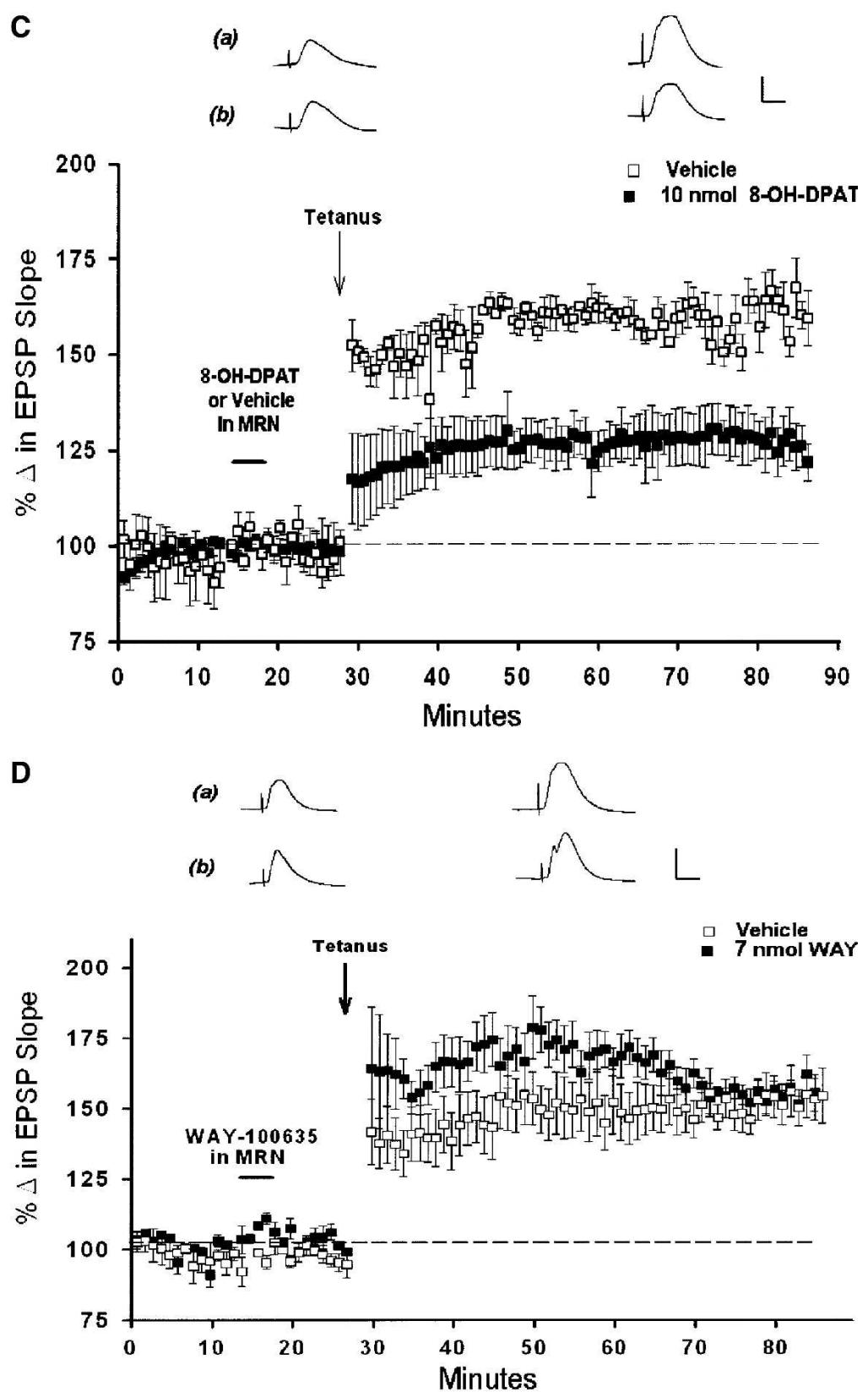

Figure 5. The 5-HT1a agonist 8-OH-DPAT attenuates LTP induction. ( $A$ ) Point plot of medial perforant path-dentate field EPSP slopes ( \pm SEM) in behaving animals, showing baseline responses, responses $30 \mathrm{~min}$ after systemic administration of $8-\mathrm{OH}$-DPAT $(0.3 \mathrm{mg} / \mathrm{kg}, \square, n=4)$ or the lactated Ringer's vehicle ( $\square),(n=4)$, and following high-frequency trains. Systemic 8-OH-DPAT had no significant effect on baseline responses, but attenuated LTP induced in the home cage $(P<0.05)$, indicating activation of 5-HT1 a receptors attenuates LTP induction, even in a familiar environment. Traces are representative of responses $25 \mathrm{~min}$ after administration of either (a) the water vehicle or (b) the 0.3 $\mathrm{mg} / \mathrm{kg}$ dose of 8-OH-DPAT, and $1 \mathrm{~h}$ after delivery of $\theta$ trains. Calibration: $1 \mathrm{mV}, 5 \mathrm{msec}$. (B) Local application of a $10 \mathrm{nmol}$ quantity of 8-OH-DPAT to the dentate region $10 \mathrm{~min}$ prior to tetanus did not attenuate LTP $(\square),(n=4)$ as compared with animals receiving only the lactated Ringer's vehicle $(\square)$, $(n=4 ; P>0.05)$. Paired traces are representative of responses $5-10 \mathrm{~min}$ after receiving either (a) vehicle or (b) a 10-nmol quantity of 8-OH-DPAT, and $1 \mathrm{~h}$ after delivery of theta trains. Calibration: 1 $\mathrm{mV}, 5 \mathrm{msec}$. (C) Local application of a 10-nmol quantity of 8-OH-DPAT directly to the MRN attenuated significantly dentate LTP induction ( $\square),(n=3)$ as compared with LTP in vehicle-only controls $(\square)$, $(n=4 ; P<0.05)$. This suggests that the attenuation of LTP by systemic 8-OH-DPAT likely is mediated by activation of 5-HT1a autoreceptors in the MRN. Traces are representative of responses $25 \mathrm{~min}$ after administration of either (a) the water vehicle or (b) the $0.3-\mathrm{mg} / \mathrm{kg}$ dose of $8-\mathrm{OH}-\mathrm{DPAT}$ and $1 \mathrm{~h}$ after delivery of theta trains. Calibration: $1 \mathrm{mV}, 5 \mathrm{msec}$. (D) Application of a 10-nmol quantity of WAY directly to the MRN had no effect on perforant path-dentate LTP induction ( $\bullet),(n=3)$ as compared with LTP induced in controls receiving an equivalent volume of lactated Ringer's $(\square),(n=4 ; P>0.05)$. Paired traces are representative responses collected 5-10 min after receiving either the lactated Ringer's vehicle (a) or $7 \mathrm{nmol}$ of WAY 100635 (b) in the MRN, and $1 \mathrm{~h}$ following delivery of theta trains. Calibration: $1 \mathrm{mV}, 5 \mathrm{msec}$. specific laminae, such as the inner or outer molecular layers, which receive commissural and lateral perforant path projections, respectively (Freund and Buzsaki 1996). Thus, dendritic disinhibition may not have been detected here because such inhibition may be restricted to lamina other than the middle molecular layer, the termination zone of the medial perforant path. Additionally, it should be noted that paired-pulse depression of field EPSPs also involves numerous synaptic processes, including presynaptic processes (McNaughton and Barnes 1977). Thus, alterations in inhibition of field EPSPs may have been obscured by other processes that also contribute to paired-pulse depression of field EPSPs. Further studies will be necessary to determine whether 5-HT1a receptor activation alters dendritic inhibition in discrete laminae. Taken together, these data suggest that a principal effect of 5-HT1a receptor activation in the dentate is excitation resulting from a phasic reduction in GABAergic inhibition, mediated presumably by the inhibition of either GABAergic interneurons or GABA release (Halasy et al. 1992; Levkovitz and Segal 1997; Gulyás et al. 1999).

How might 5-HT1a receptor activation contribute to the induction of perforant path-granule cell LTP? Treatments that attenuate GABAergic inhibition are known to facilitate LTP induction (Wigstrom and Gustafsson 1985). Thus, we speculate that the serotonin-mediated inhibition of GABAergic interneurons may be necessary for reducing GABAergic inhibition, an effect that appears necessary for the full induction of dentate LTP. This possibility is supported by prior reports showing that MRN stimulation can facilitate tetanusinduced short-term potentiation (STP) in the dentate (Klancnik and Phillips 1991). Likewise, we also observed a significant dose-dependent reduction in STP following theta trains delivered in the presence of WAY. Because STP in the dentate is dependent upon NMDA receptor activation enabled by the degree of local postsynaptic depolarization (Anwyl et al. 1989), these observations are consistent with the view that 5-HT1a receptor activation enhances postsynaptic depolarization by attenuating GABAergic inhibition. Such an effect would facilitate NMDA receptor activation and LTP induction, as hypothesized previously (Freund et al. 1990; Halasy et al. 1992; Gulyás et al. 1999).

Although 8-OH-DPAT exerts disinhibitory effects, application of $8-\mathrm{OH}$ DPAT directly to the dentate gyrus did not facilitate LTP induction, an effect 
that would be expected if 5-HT1a receptor activation reduced GABAergic inhibition. However, the disinhibitory effects of 5-HT1a receptor activation were immediate and short-lived (5-10 min including the period of administration). Thus, the disinhibitory effects may have been absent when LTP was induced at 15 min following 8-OH-DPAT application. In addition, 5-HT1a re-
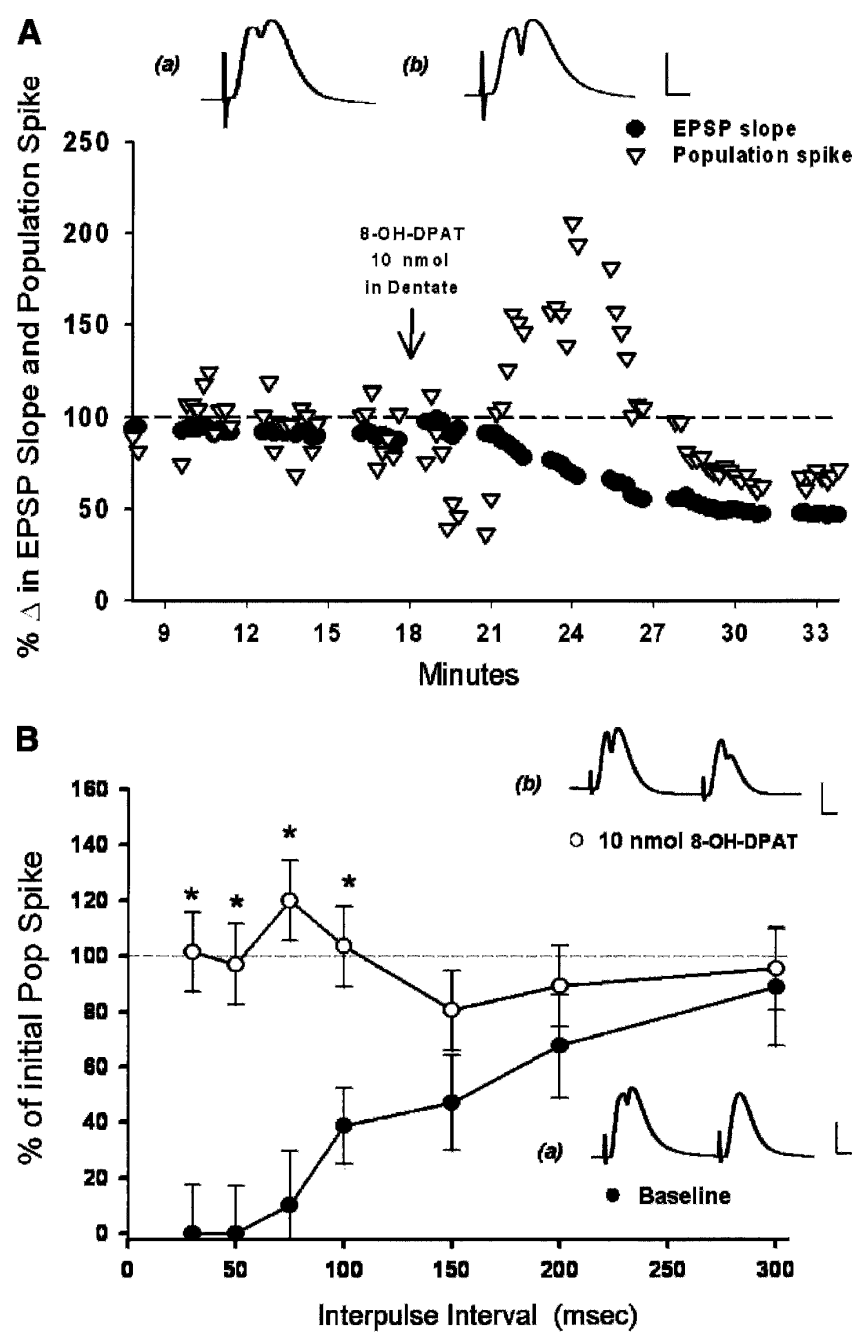

C
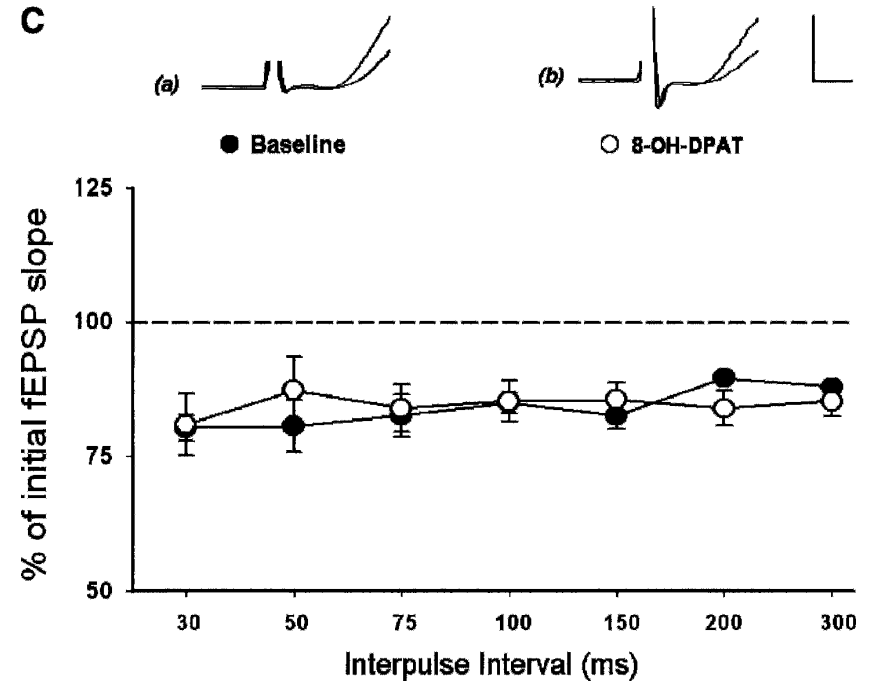

ceptor agonists also attenuated synaptic responses, possibly via the hyperpolarization of granule cells via 5-HT1a receptors on the granule cells themselves (Piguet and Galvan 1994). Thus, this longer-lasting inhibition of synaptic responses may have obscured any facilitation of LTP that otherwise might have resulted from the disinhibitory effects of 8-OH-DPAT.

\section{5-HTla antagonists block dentate LTP during} exploration of novel, but not familiar, environments

The principal effect observed here was that the highest dose of WAY was effective in attenuating LTP induction, but only while animals explored a novel environment. WAY had no effect on LTP induced while animals explored familiar environments. These behavior-specific effects may be related to GABAergic inhibition during hippocampal states that are associated with exploration and encoding (Moser 1996; Paulsen and Moser 1998). Novel environments phasically increase dentate population spikes (Kitchigina et al. 1997; Davis et al. 2004), an effect involving a reduction in somatic inhibition (Moser 1996). In contrast, dendritic inhibition in the dentate is enhanced under these same conditions (Moser 1996; Paulsen and Moser 1998). The combination of these effects is thought to act as a filter that amplifies the output only of the most strongly activated granule cells (Moser 1996; Paulsen and Moser 1998; Davis et al. 2004). In this view, neuromodulators are suggested to regulate synaptic plasticity during encoding by initiating a global increase in inhibition and a concomitant disinhibition of select synaptic regions or neuronal populations, possibly by the very same neuromodulator (Paulsen and Moser 1998). As learning tasks in novel contexts also enhance hippocampal serotonin levels (Wilkson et al. 1996), these data support the interpretation that serotonin and the activation of 5-HT1a receptors contribute to synaptic plasticity in the dentate by attenuating the enhanced GABAergic inhibition observed when animals explore novel environments (Moser 1996).

Paradoxically, whereas the effect of WAY in behaving rats depends upon novel stimuli, application of WAY to the dentate also blocked LTP induction in rats anesthetized with pentobarbital. This supports the view that the effect of systemic WAY on LTP is mediated by the blockade of 5-HT1a receptors within the dentate gyrus. However, this indicates LTP induction is blocked

Figure 6. The 5-HT1 a agonist 8-OH-DPAT attenuates paired pulse inhibition. The 5-HT1a agonist 8-OH-DPAT exerts phasic excitatory and disinhibitory effects. (A) Example of the excitatory effect of 8-OH-DPAT when applied to the dentate gyrus. A 10-nmol quantity applied to the dentate hilar region in pentobarbital anesthetized animals produced a phasic increase in the dentate population spike amplitude $(\nabla)$. This was accompanied by a slowly developing attenuation of field EPSP slopes $(\bullet)$. Traces show representative responses before (a) and 5 min after (b) 8-OH-DPAT administration. Calibration: $1 \mathrm{mV}, 5 \mathrm{msec}$. (B) Point plot of paired-pulse inhibition (PPI) of medial perforant path-dentate population spikes ( \pm SEM) with paired-pulse inter-stimulus intervals (ISIs) of 30-300 msec. Local application of 8-OH-DPAT $(10 \mathrm{nmol})$ phasically attenuated the inhibition of the second pop spike at intervals of 30-300 msec (•) $(n=4)$ when compared with inhibition observed prior to drug application $(0),(n=4),(*)(P<0.05)$. Traces show paired responses evoked at 30 msec ISIs before (a) and after (b) 8-OH-DPAT application. Calibration: $1 \mathrm{mV}, 5 \mathrm{msec}$. (C) Point plot of paired-pulse depression (PPD) of medial perforant path-dentate synaptic responses ( \pm SEM) with paired-pulse ISIs of 30-300 msec. Local application of 8-OH-DPAT $(10 \mathrm{nmol})$ had no effect on paired-pulse inhibition of the second field EPSP normally observed at intervals of 30-300 msec. Shown is percent inhibition of field EPSP slopes at baseline $(\bullet),(n=4)$ as compared with inhibition observed following application of a $10-\mathrm{nmol}$ quantity of DPAT $(0),(n=4, P>0.05)$. Traces show representative paired field EPSP slopes taken at a 30-msec ISI before (a) and after (b) application of $10 \mathrm{nmol}$ of 8-OH-DPAT. Calibration: $0.5 \mathrm{mV}, 0.5 \mathrm{msec}$. 
by WAY in both behaving animals in novel environments and in animals under pentobarbital anesthesia. What could account for the similar effect of WAY on LTP in these two very different behavioral states? One explanation is that GABAergic inhibition in these two states is greatly increased. Pentobarbital anesthesia enhances GABAergic inhibition (Alger and Nicoll 1979), and a phasic enhancement of dendritic inhibition is observed in the dentate gyrus when animals explore a novel environment (Moser 1996; Paulsen and Moser 1998). Thus, we speculate that both pentobarbital-anesthetized animals and animals exploring novel environments are similar in that both conditions are associated with enhanced GABAergic inhibition. In this view, WAY blocks LTP in both states by blocking the disinhibitory effect of 5-HT1a receptor activation that normally is necessary for LTP induction during periods of enhanced GABAergic inhibition (Paulsen and Moser 1998; Davis et al. 2004).

Previously, we reported that novel environments facilitate the induction and maintenance of perforant path-dentate LTP, suggesting novelty may engage the hippocampal formation in a "mode" that is particularly conducive to synaptic plasticity and encoding (Paulsen and Moser 1998; Buzsaki 1989; Hasselmo et al. 2002; Lisman and Otmakhova 2002; Davis et al. 2004). We suggest this "mode" involves the phasic disinhibitory effects of dentate 5-HT1a receptor activation. Moreover, serotonin enhances dentate spikes and granule cell output to the CA3 region, output thought crucial for encoding new information by virtue of the hypothesized "detonator" function of mossy fiber synapses (McNaughton and Morris 1987; Henze et al. 2002). Because dentate activity and dentate output are thought crucial for the encoding of new information in the hippocampus (McNaughton et al. 1989), these data suggest that serotonin and 5-HT1a receptors, implicated previously in novelty and learning (Wilkinson et al. 1996; Buhot 1997; Sarnyai et al. 2000), have dual roles in the dentate gyrus. In this view, 5-HT1a receptors contribute to encoding by enhancing both dentate synaptic plasticity, as well as granule cell output to the CA3 region, effects that can be attributed to the disinhibitory actions of dentate 5-HT1a receptor activation. The enhancement of dentate LTP and dentate output to the CA3 region by 5 -HT1a receptors suggest that serotonin and 5-HT1a receptors contribute to dentate LTP induction, primarily during behavioral states associated with acquisition and encoding of novel, hippocampus-relevant information.

\section{Materials and Methods}

All experiments were performed in accordance with NIH guidelines for the care and use of animals in research. Adult male Fischer 344 rats (300-400 g, Harlan laboratories) were anesthetized with pentobarbital sodium (60 mg/kg i.p.), mounted in a stereotaxic frame, and maintained at $37^{\circ} \mathrm{C}$ with a thermal pad. Medial perforant path responses were evoked by stimulation of the extreme dorsomedial aspect of the angular bundle for medial perforant path activation $[\mathrm{AP}-8.1, \mathrm{ML}+2.5, \mathrm{DV}+2.5 \mathrm{~mm}$ from Bregma, using the coordinates of Paxinos and Watson (1994)]. Dentate field responses were recorded using a single wire or insulated cannula placed in the hilar region $(\mathrm{AP}-3.5, \mathrm{ML}+2.5, \mathrm{DV}$ $-3.3 \mathrm{~mm}$; Fig. 1). In experiments using pentobarbital anesthetized animals, a surgical level of anesthesia was maintained by supplemental injections of pentobarbital $(20 \mathrm{mg} / \mathrm{kg} / \mathrm{h})$.

In experiments assessing the effects of WAY-100635 in awake, freely moving animals, male Fischer 344 rats were implanted with permanent electrodes as described previously (Villarreal et al. 2002; Davis et al. 2004). Briefly, all surgeries were performed under sterile conditions, and electrodes were fitted with gold Amphenol pins, inserted into a plastic connector, and affixed to the skull using dental acrylic. Following surgery, animals were given ibuprofen $(30 \mathrm{mg} / \mathrm{kg} / \mathrm{d})$ and 90,000 units of Penicillin G (i.m.), and allowed to recover for a 2 -wk period.
In studies using either anesthetized or behaving animals, stimulation (biphasic constant current pulses, 0.1 msec duration/ phase) was delivered to the perforant path via bipolar electrodes constructed from two twisted Teflon-coated stainless steel wires (0.008 $\mathrm{mm}$ diameter, A-M Systems). Perforant path responses were evoked at intensities eliciting field EPSP slopes that were $50 \%$ of their asymptotic magnitude, as determined using current intensities ranging from 10-550 $\mu \mathrm{A}$. Responses were evoked at a rate of $0.066 \mathrm{~Hz}$, filtered at $0.3-100 \mathrm{kHz}$, and amplified $1000 \times$ using a differential AC amplifier with a skull screw serving as the indifferent electrode.

In studies using behaving animals with permanently implanted electrodes, the highly selective (Fletcher et al. 1996) 5-HT1a receptor antagonist WAY-100635 maleate (N-[2-[4-(2methoxyphenyl)-1-piperazinyl] ethyl]-N-(2-pyridinyl)cyclohexanecarboxamide trihydrochloride; RBI/Sigma) was dissolved in water and administered intraperitoneally. The 5-HT1a agonist 8-OH-DPAT ([ \pm ]) 8-hydroxy-2-(di-n-propylaminotetralin; RBI/ Sigma) was administered systemically in a dose (8-OH-DPAT, $0.3 \mathrm{mg} / \mathrm{kg}$ i.p.) found previously to activate $5-\mathrm{HT} 1 \mathrm{a}$ receptors in vivo (Cadogan et al. 1994; Nitz and McNaughton 1999).WAY$100635,8-O H-D P A T$, or equivalent volumes of the water vehicle were administered intraperitoneally $30 \mathrm{~min}$ prior to delivery of theta trains.

Our previous studies indicate that the induction and longevity of LTP are increased significantly when LTP is induced during exploration of novel, or "enriched" environments (Davis et al. 2004). In the present studies, LTP was induced in two conditions, i.e., animals were (1) lifted and placed in a cage identical to the home cage, save that it contained a variety of novel objects (funnels, small metal or plastic toys, etc.) or (2) lifted and reoriented in their familiar home cage, so as to control for handling effects. Five minutes after placement in the novel or home cage (25 min after drug or vehicle administration), trains of theta burst stimulation were delivered to the medial perforant path using the same current intensity used to evoke low frequency responses. Each theta train consisted of five $25 \mathrm{msec}, 400 \mathrm{~Hz}$ bursts (10 pulses/burst) delivered at 200-msec intervals (total train duration $925 \mathrm{msec}$ ). LTP was induced by delivering five theta trains at 20-sec intervals. EEG was monitored following delivery of each train, and none displayed afterdischarges following tetanization. Immediately after delivery of the last train, animals were either returned to or reoriented in their home cages (Davis et al. 2004). Perforant path-dentate responses were then collected in the animal's home cage for an additional hour after tetanus. In these experiments, total activity over the 5-min period of exploration and train delivery was measured using an activity monitor (Videomex-V, Columbus Inst.), which analyzes motion by a pixel-by-pixel analysis of contrast changes within the cage area $\left(1080 \times 3250\right.$ pixels $\left./ \mathrm{cm}^{2}\right)$. Activity during exploration of novel or familiar environments is expressed as the total number of pixels detecting contrast change over the 5-min exploration period.

The magnitude of drug effects on synaptic responses in behaving animals is expressed as the percent change in the slope $(\mathrm{dV} / \mathrm{dt})$ of the field EPSP measured during the 5-10-min period following drug or vehicle application, and as compared with the mean slope of responses of the last $5 \mathrm{~min}$ of baseline prior to drug application. The magnitude of LTP is expressed as the percent change in the field EPSP slopes measured 56-60 min posttetanus, when compared with responses collected during the last $5 \mathrm{~min}$ of baseline. The time course of LTP was followed by collecting and averaging 10 evoked responses each day in the animal's home cage for a period of $2 \mathrm{wk}$. LTP, over days, is expressed as the percent change in response magnitude of averaged field EPSP slopes as compared with baseline responses collected over the 3-d period prior to LTP induction. In some experiments, population spikes were measured to assess alterations in recurrent inhibition. Spike amplitudes were measured from the lead peak (onset) to the trough of the spike using commercially available software (DataWave Technologies).

In studies using the acute in vivo preparation to assess the effects of local application of WAY and 8-OH-DPAT on LTP in- 
duction, animals were anesthetized with pentobarbital $(60 \mathrm{mg} /$ $\mathrm{kg}$ ) and were maintained at surgical levels of pentobarbital anesthesia $(20 \mathrm{mg} / \mathrm{kg} / \mathrm{hr})$. A cannulatrode constructed from an Epoxylite-coated, 33-gauge stainless steel cannula exposed only at the tip was lowered into the hilar region of the dentate gyrus. The cannulatrode allowed for recording of field EPSPs at the site of drug application. In these experiments, baseline responses were collected at a rate of $0.066 \mathrm{~Hz}$ for at least $20 \mathrm{~min}$, after which WAY (1, 3, and $7 \mathrm{nmol}$ quantities) or 8 -OH-DPAT (10 nmol) were dissolved in lactated Ringer's solution, and delivered in a $1-\mu \mathrm{L}$ volume to the hilar region through the stainless-steel cannulatrode via pressure ejection $(0.20 \mu \mathrm{L} / \mathrm{min}$, for $5 \mathrm{~min})$. In some experiments, 8-OH-DPAT $(10 \mathrm{nmol}), \mathrm{WAY}(7 \mathrm{nmol})$, or the lactated Ringer's vehicle was applied to the MRN (AP - 7.9 mm, ML $+1.5 \mathrm{~mm}, \mathrm{DV},-8.1 \mathrm{~mm}$, entry at a $10^{\circ}$ angle; Nitz and McNaughton 1999). This quantity was shown previously to block raphe activity, serotonin release, and dentate interneuron activity (see Nitz and McNaughton 1999). After cessation of local drug delivery, medial perforant path responses were collected for an additional $10 \mathrm{~min}$ at the rate of $0.066 \mathrm{~Hz}$. LTP was then induced by delivery of five theta trains as described above. Responses were collected at $0.066 \mathrm{~Hz}$ for an additional hour after delivery of trains.

LTP magnitude induced in anesthetized animals is expressed as the percent change in the slope of the field EPSP measured 56-60 min after tetanus as compared with the mean slope of field EPSPs measured over the last $5 \mathrm{~min}$ of pre-drug baseline. Additionally, we assessed short-term potentiation (STP), an increase in synaptic responses observed immediately after tetanus (Anwyl et al. 1989). The magnitude of STP produced by moderate intensity theta bursts in vivo is less prominent than STP observed following intense high-frequency trains (Davis et al. 2004), although STP is evident in the amplitudes of responses observed 1-5 min after theta bursts and here served as a measure of initial short-term potentiation. STP is expressed as the percent change in the field EPSP slopes measured over the 5-min period following delivery of theta trains as compared with baseline responses collected during the last $5 \mathrm{~min}$ of baseline prior to drug application.

Both dose-response effects of WAY on baseline responses and LTP magnitude were evaluated only in normally distributed data using a single $d f$ one-way analysis of variance (ANOVA; see Keppel and Zedeck 1991). LTP magnitude over days, doseresponse effects, and drug effects on paired pulse inhibition were assessed using a two-way repeated measures ANOVA, and post hoc Tukey tests. Electrode placements were verified by stereotaxic coordinates, audio localization of the CA1, and dentate cell layers, as well as evoked response characteristics usually observed in the dentate (McNaughton and Barnes 1977). Cannula tip placement in the MRN was verified in each animal using standard histological methodology.

\section{Acknowledgments}

Supported by NS 39409 (B.E.D.), GM 45043 (F.L.J.), and the Alfred P. Sloan Foundation (D.D.). We thank Clyde Phelix and Julie Hensler for helpful discussions, and Brandon Goertz for technical assistance.

\section{References}

Alger, B.E. and Nicoll, R.A. 1979. GABA-mediated biphasic inhibitory responses in hippocampus. Nature 281: 315-317.

Anwyl, R., Mulkeen, D., and Rowan, M.J. 1989. The role of $N$-methyl-D-aspartate receptors in the generation of short-term potentiation in the rat hippocampus. Brain Res. 503: 148-151.

Bliss, T.V.P. and Collingridge, G.L. 1993. A synaptic model of memory: Long-term potentiation in the hippocampus. Nature 361: 31-39.

Bliss, T.V.P. and Lomo, T. 1973. Long-lasting potentiation of synaptic transmission in the dentate area of the anaesthetized rabbit following stimulation of the perforant path. J. Physiol. 232: 331-356.

Bliss, T.V., Goddard, G.V., and Riives, M. 1983. Reduction of long-term potentiation in the dentate gyrus of the rat following selective depletion of monoamines. J. Physiol. 334: 475-491.

Bramham, C.R., Bacher-Svendsen, K., and Sarvey, J.M. 1997. LTP in the lateral perforant path is $\beta$-adrenergic receptor-dependent. Neuroreport 8: 719-724.

Buhot, M.C. 1997. Serotonin receptors in cognitive behaviors. Curr. Opin. Neurobiol. 7: 243-254.

Buhot, M.C. and Naili, S. 1995. Changes in exploratory activity following stimulation of hippocampal 5-HT1A and 5-HT1B receptors in the rat. Hippocampus 5: 198-208.

Buzsaki, G. 1989. Two-stage model of memory trace formation: A role for "noisy" brain states. Neuroscience 31: 551-570.

Cadogan, A.K., Kendall, D.A., and Marsden, C.A. 1994. Serotonin 5-HT1a receptor activation increases cyclic AMP formation in the hippocampus in vivo. J. Neurochem. 62: 1816-1821.

Davis, C. and Derrick, B.E. 1997. Exposure to a novel environment facilitates LTP induction at medial perforant path-dentate synapses in awake, freely moving animals. Soc. Neurosci. Abst. 23: 788.

Davis, C., Jones, F.L., and Derrick, B.E. 2004. Novelty enhances the induction and maintenance of LTP in the dentate gyrus. J. Neurosci. 24: 6497-6506.

Davis-Hart, C. and Derrick, B.E. 2001. Novel environments facilitate long-term potentiation through 5-HT1A receptors in the dentate gyrus. Soc. Neurosci. Abst. http://sfn.scholarone.com/itin2001/.

Erickson, C.A., McNaughton, B.L., and Barnes, C.A. 1993. Comparison of long-term enhancement and short-term exploratory modulation of perforant path synaptic transmission. Brain Res. 615: 275-280.

Fletcher, A., Forster, E.A., Bill, D.J., Brown, G., Cliffe, I.A., Hartley, J.E. Jones, D.E., McLenachan, A., Stanhope, K.J., Critchley, D.J., et al. 1996. Electrophysiological, biochemical and behavioural studies with WAY-100635, a potent, selective and silent 5-HT1A receptor antagonist. Behav. Brain Res. 73: 337-353.

Freund, T.F. 1992. GABAergic septal and serotonergic median raphe afferents preferentially innervate inhibitory interneurons in the hippocampus and dentate gyrus. Epilepsy Res. Suppl. 7: 79-91.

Freund, T.F. and Buzsaki, G. 1996. Interneurons of the hippocampus. Hippocampus 6: 347-470.

Freund, T.F., Gulyás, A.I., Acsady, L., Gorcs, T., and Toth, K. 1990. Serotonergic contro of the hippocampus via local inhibitory interneurons. Proc. Natl. Acad. Sci. 87: 8501-8505.

Gulyás, A.I., Acsády, L., and Freund, T.F. 1999. Structural basis of the cholinergic and serotonergic modulation of GABAergic neurons in the hippocampus. Neurochem. Intl. 34: 359-372.

Guzowski, J.F., Knierim, J.J., and Moser, E.I. 2004. Ensemble dynamics of hippocampal regions CA3 and CA1. Neuron 44: 581-584.

Halasy, K., Miettinen, R., Szabat, E., and Freund, T.F. 1992. GABAergic interneurons are the major postsynaptic targets of median raphe afferents in the rat dentate gyrus. Eur. J. Neurosci. 4: 144-153.

Hasselmo, M.E., Bodelon, C., and Wyble, B.P. 2002. A proposed function for hippocampal theta rhythm: Separate phases of encoding and retrieval enhance reversal of prior learning. Neural Comput. 14: 793-781.

Henze, D.A., Wittner, L., and Buzsaki, G. 2002. Single granule cells reliably discharge targets in the hippocampal CA3 network in vivo. Nat. Neurosci. 5: 790-795.

Hjorth, S. and Magnusson, T. 1988. The 5-HT 1A receptor agonist, 8-OH-DPAT, preferentially activates cell body 5-HT autoreceptors in rat brain in vivo. Naunyn Schmiedebergs Arch. Pharmacol. 338: 463-471.

Jolas, T., Schreiber, R., Laporte, A.M., Chastanet, M., De Vry, J., Glaser, T., Adrien, J., and Hamon, M. 1995. Are postsynaptic 5-HT1A receptors involved in the anxiolytic effects of 5-HT1A receptor agonists and in their inhibitory effects on the firing of serotonergic neurons in the rat? J. Pharmacol. Exp. Ther. 272: 920-929.

Kao, K., Sanders, M.J., and Green, E. 1997. Physiological evidence for hippocampal disinhibition resulting from the activation of the median raphe. Brain Res. 752: 90-98.

Kemp, A. and Manahan-Vaughan, D. 2004. Hippocampal long-term depression and long-term potentiation encode different aspects of novelty acquisition. Proc. Natl. Acad. Sci. 101: 8192-8197.

Keppel, G. and Zedeck, S. 1991. Data analysis for research design, pp. 474. Prentice-Hall, Upper Saddle River, NJ.

Kitchigina, V., Vankov, A., Harley, C., and Sara, S.J. 1997. Novelty-elicited, noradrenaline-dependent enhancement of excitability in the dentate gyrus. Eur. J. Neurosci. 9: 41-47.

Klancnik, J.M. and Phillips, A.G. 1991. Modulation of synaptic plasticity in the dentate gyrus of the rat by electrical stimulation of the median raphe nucleus. Brain Res. 557: 236-240.

Klancnik, J.M., Baimbridge, K.G., and Phillips, A.G. 1989. Increased population spike amplitude in the dentate gyrus following systemic administration of 5-hydroxytryptophan or 8-hydroxy-2-(di-n-propylamino)tetralin. Brain Res. 505: 145-148.

Kojima, T., Matsumoto, M., Togashi, H., Tachibana, K., Kemmotsu, O., and Yoshioka, M. 2003. Fluvoxamine suppresses the long-term potentiation in the hippocampal CA1 field of anesthetized rats: An 
effect mediated via 5-HT1A receptors. Brain Res. 959: 165-168.

Kreiss, D.S. and Lucki, I. 1994. Differential regulation of serotonin (5-HT) release in the striatum and hippocampus by 5-HT1A autoreceptors of the dorsal and median raphe nuclei. J. Pharmacol. Exp. Ther. 269: 1268-1279.

Levkovitz, Y. and Segal, M. 1997. 5-HT1A receptors modulate hippocampal reactivity to afferent stimulation. J. Neurosci. 17: 5591-5598.

Li, S., Cullen, W.K., Anwyl, R., and Rowan, M.J. 2003. Dopamine-dependent facilitation of LTP induction in hippocampal CA1 by exposure to spatial novelty. Nat. Neurosci. 6: 526-531.

Lisman, J.E. and Otmakhova, N.A. 2002. Storage, recall, and novelty detection of sequences by the hippocampus: Elaborating on the SOCRATIC model to account for normal and aberrant effects of dopamine. Hippocampus 11: 551-568.

Marchetti, E., Chaillan, F.A., Dumuis, A., Bockaert, J., Soumireu-Mourat, B., and Roman, F.S. 2004. Modulation of memory processes and cellular excitability in the dentate gyrus of freely moving rats by a 5-HT4 receptors partial agonist, and an antagonist. Neuropharmacology 47: 1021-1035.

McNaughton, B.L. and Barnes, C.A. 1977. Physiological identification and analysis of dentate granule cell responses to stimulation of the medial and lateral perforant pathways in the rat. J. Comp. Neurol. 175: 439-454.

McNaughton, B.L. and Morris, R.G.M. 1987. Hippocampal synaptic enhancement and information storage within a distributed memory system. Trends Neurosci. 10: 408-415.

McNaughton, B.L., Barnes, C.A., Meltzer, J., and Sutherland, R.J. 1989. Hippocampal granule cells are necessary for normal spatial learning but not for spatially-selective pyramidal cell discharge. Exp. Brain Res. 76: 485-496.

Moser, E.I. 1996. Altered inhibition of dentate granule cells during spatial learning in an exploration task. J. Neurosci. 16: 12471259.

Moser, E., Mathiesen, I., and Andersen, P. 1993. Association between brain temperature and dentate field potentials in exploring and swimming rats. Science 259: 1324-1326.

Mundey, M.K., Fletcher, A., and Marsden, C.A. 1996. Effects of 8-OHDPAT and 5-HT1 antagonists WAY100135 and WAY100635, on guinea-pig behaviour and dorsal raphe 5-HT neurone firing. $\mathrm{Br}$. J. Pharmacol. 117: 750-756.

Nitz, D.A. and McNaughton, B.L. 1999. Hippocampal EEG and unit activity responses to modulation of serotonergic median raphe neurons in the freely behaving rat. Learn. Mem. 6: 153-167.

Paulsen, O. and Moser, E. 1998. A model of hippocampal memory encoding and retrieval GABAergic control of synaptic plasticity. Trends Neurosci. 21: 273-278.

Paxinos, G. and Watson, C. 1994. Stereotaxic atlas of the rat brain, 2nd ed., plate 50. Academic Press, New York.

Piguet, P. and Galvan, M. 1994. Transient and long-lasting actions of 5-HT on rat dentate gyrus neurones in vitro. J. Physiol. 481: 629-639.
Richter-Levin, G., and Segal, M. 1990. Effects of serotonin releasers on dentate granule cell excitability in the rat. Exp. Brain Res. 82: 199-207.

Sakai, N. and Tanaka, C. 1993. Inhibitory modulation of long-term potentiation via the 5 -HT1A receptor in slices of the rat hippocampal dentate gyrus. Brain Res. 613: 326-330.

Sarnyai, Z., Sibille, E.L., Pavlides, C., Fenster, R.J., McEwen, B.S., and Toth, M. 2000. Impaired hippocampal-dependent learning and functional abnormalities in the hippocampus in mice lacking serotonin (1A) receptors. Proc. Natl. Acad. Sci. 97: 14731-14736.

Segal, M. 1990. Serotonin attenuates a slow inhibitory postsynaptic potential in rat hippocampal neurons. Neuroscience 36: 631-641.

Srebro, B., Azmitia, E.C., and Winson, J. 1982. Effect of 5-HT depletion of the hippocampus on neuronal transmission from perforant path through dentate gyrus. Brain Res. 235: 142-147.

Stanton, P. and Sarvey, J. 1985. Depletion of norepinephrine, but not serotonin, reduces LTP of the dentate gyrus of rat hippocampal slices. J. Neurosci. 5: 2169-2176.

Straube, T., Korz, V., and Frey, J.U. 2003a. Bidirectional modulation of long-term potentiation by novelty-exploration in rat dentate gyrus. Neurosci. Lett. 344: 5-8.

Straube, T., Korz, V., Balschun, D., and Frey, J.U. 2003b. Requirement of $\beta$-adrenergic receptor activation and protein synthesis for LTP-reinforcement by novelty in rat dentate gyrus. J. Physiol. 552: 953-960.

Tachibana, K., Matsumoto, M., Togashi, H., Kojima, T., Morimoto, Y., Kemmotsu, O., and Yoshioka, M. 2004. Milnacipran, a serotonin and noradrenaline reuptake inhibitor, suppresses long-term potentiation in the rat hippocampal CA1 field via 5-HT1A receptors and $\alpha$ 1-adrenoceptors. Neurosci. Lett. 357: 91-94.

Terreni, L., Gemma, C., and De Simoni, M.G. 1996. Electrically-evoked 5-hydroxytryptaminew efflux in rat hypothalamus studied using in vivo amperometry. J. Neurosci. Methods 68: 71-79.

Villarreal, D.M., Do, V., Haddad, E., and Derrick, B.E. 2002. NMDA receptor antagonists sustain LTP and spatial memory: Active processes mediate LTP decay. Nat. Neurosci. 5: 48-52.

Vinogradova, O.S. 2001. Hippocampus as comparator: Role of the two input and two output systems of the hippocampus in selection and registration of information Hippocampus 11: 578-598.

Wigstrom, H. and Gustafsson, B. 1985. Facilitation of hippocampal long-lasting potentiation by GABA antagonists. Acta Physiol. Scand. 125: $159-172$.

Wilkinson, L.S., Humby, T., Killcross, S., Robbins, T.W., and Everitt, B.J. 1996. Dissociations in hippocampal 5-hydroxytryptamine release in the rat following Pavlovian aversive conditioning to discrete and contextual stimuli. Eur. J. Neurosci. 8: 1479-1487.

Winson, J. 1980. Influence of raphe nuclei on neuronal transmission from perforant pathway through dentate gyrus. J. Neurophysiol. 4: 937-950.

Received June 23, 2005; accepted in revised form November 14, 2005.

\section{Learning \& Memory}




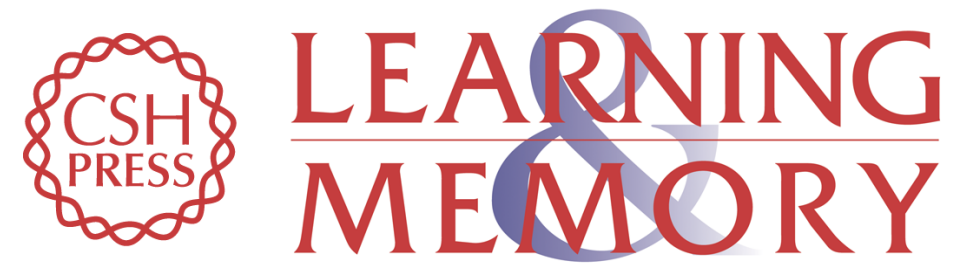

\section{5-HT1a receptor antagonists block perforant path-dentate LTP induced in novel, but not familiar, environments}

Cyndy Davis Sanberg, Floretta L. Jones, Viet H. Do, et al.

Learn. Mem. 2006, 13:

Access the most recent version at doi:10.1101//m.126306

References This article cites 59 articles, 11 of which can be accessed free at: http://learnmem.cshlp.org/content/13/1/52.full.html\#ref-list-1

License

Email Alerting Receive free email alerts when new articles cite this article - sign up in the box at the Service top right corner of the article or click here. 